\section{OPEN ACCESS}

Edited by:

Alexander S. Apt,

Central Tuberculosis Research Institute (RAMS), Russia

Reviewed by:

Christoph Hölscher, Research Center Borstel

(LG), Germany

Javier Rangel-Moreno,

University of Rochester, United States

*Correspondence:

Gina R. Leisching

gina.leisching@gmail.com

Specialty section:

This article was submitted to

T Cell Biology,

a section of the journal

Frontiers in Immunology

Received: 19 June 2019 Accepted: 18 October 2019 Published: 01 November 2019

Citation:

Leisching GR (2019) P/3-Kinase $\delta y$ Catalytic Isoforms Regulate the Th-17 Response in Tuberculosis.

Front. Immunol. 10:2583.

doi: 10.3389/fimmu.2019.02583

\title{
PI3-Kinase $\delta \gamma$ Catalytic Isoforms Regulate the Th-17 Response in Tuberculosis
}

Gina R. Leisching *

SA MRC Centre for TB Research, DST-NRF Centre of Excellence for Biomedical Tuberculosis Research, Division of Molecular Biology and Human Genetics, Faculty of Medicine and Health Sciences, Stellenbosch University, Cape Town, South Africa

Although IL17A plays a protective role at the mucosal surface, when IL17A signaling becomes dysregulated, a pathological response is locally induced. At the early stages of Mycobacterium tuberculosis (M.tb) infection, IL17A contributes to granuloma formation and pathogen containment. In contrast, during disease progression, a dysregulated IL17A hyperinflammatory response drives tissue destruction through enhanced neutrophil recruitment. Cumulative research has implicated the PI3-Kinase pathways as one of the most relevant in the pathophysiology of inflammation. Evidence shows that IL-17A secretion and the expansion of the Th17 population is dependant in PI3-Kinase signaling, with the p110 $\mathrm{\delta}$ and $\mathrm{p} 110 \gamma$ isoforms playing a prominent role. The $\mathrm{p} 110 \gamma$ isoform promotes disease progression through dampening of the Th17 response, preventing pathogen clearance and containment. The p110 $\gamma$ gene, PIK3CG is downregulated in TB patients during late-stage disease when compared to healthy controls, demonstrating an important modulatory role for this isoform during TB. Conversely, the p110 isoform induces IL-17A release from pulmonary $\gamma \delta$ T-cells, committed Th17 cells and promotes neutrophil recruitment to the lung. Inhibiting this isoform not only suppresses IL-17A secretion from Th17 cells, but it also inhibits cytokine production from multiple T-helper cell types. Since increased IL-17A levels are observed to be localized in the lung compartments (BAL and lymphocytes) in comparison to circulating levels, an inhalable PI3K $\delta$ inhibitor, which is currently utilized for inflammatory airway diseases characterized by IL-17A over-secretion, may be a therapeutic option for active TB disease.

Keywords: tuberculosis, IL-17A, PI3-Kinase, Th17, neutrophils, airway inflammation

\section{INTRODUCTION}

IL-17A is mostly active at mucosal sites and plays a primarily protective role at the lung surface through bridging the gap between the innate and adaptive immune responses $(1,2)$. Dysregulated signaling upstream or downstream may therefore greatly affect feedback loops during an inflammatory or infectious episode. Its potential of IL-17A to mediate a pathological immune response is especially observed at the intestinal, skin, and lung mucosa. Diseases such as colitis, inflammatory bowel disease (IBD), dermatitis, psoriasis, asthma, and chronic obstructive 
pulmonary disease (COPD) caused by chronic inflammation are rooted by dysregulated IL-17A signaling (3-7). Its role in potentiating chronic inflammatory diseases is so significant, that targeting of the IL-17A pathway is a major focus of antiinflammatory drug development (8).

The immunopathological potential of IL-17A during autoimmune and infectious episodes suggests that IL-17A may have a detrimental effect in chronic bacterial infections such as tuberculosis (TB), particularly during late stages of disease (9). In resistant hosts, IL-17A contributes to the formation of a mature granuloma $(10,11)$ which constrains the multiplication of Mycobacterium tuberculosis (M.tb) clinical isolates and plays a protective role (12). This is particularly observed during infection with hypervirulent M.tb strains. A recent paper by Erdmann and colleagues describes the ability of IL-17A to contribute to the expansion of IFN- $\gamma$-, IL-2- and TNF-secreting multifunctional T cells in IL-27R $\alpha^{-/-}$mice, and that the level of IL-17A induction is essential for the accumulation of these cells during infection $(13,14)$. It was also observed that IL-17A, but not IFN- $\gamma$, is critical for mucosal vaccine-induced immunity against M.tb (14). On the other hand, Th17 cells have been implicated in the pathology of TB through inducing exacerbated neutrophil recruitment which enhances inflammation and pleural tissue damage in during disease (3). Even though IL-17 production may be required for early granuloma formation, it's chronic or exacerbated secretion may also be detrimental as it promotes neutrophil accumulation which compromises the generation of a stable mononuclear granuloma. Granuloma turnover then becomes dysregulated which leads to liquefactive necrosis and pathological scarring (15-17). Cumulative evidence suggests that IL-17A-induced pathology is significant during late-stage disease rather than during early infection $(3,18,19)$, however delineating IL-17A signaling during both stages could promote the development of specific immunotherapeutic interventions that target key molecules within this pathway, and in doing so, improve current treatment regimes.

It has been observed that in patients with active TB, not only do they have a lower proportion of circulating Th17 cells (20), but plasma levels of IL-17A are also lower when compared to healthy individuals or those with latent TB infection (LTBI) (21). IL-17A is found to be increased in bronchoalveolar lavage (BAL) fluid of TB patients (17) and in lymphocytes surrounding pulmonary granulomas (17). In mice studies, it was observed that IL17RA (IL-17A receptor) is expressed in non-hematopoietic cells (endothelial and epithelial cells, as well as fibroblasts) in the lungs of $M$.tb infected mice $(18,22)$. Thus, during late-stage disease, IL-17A appears to play a predominant role within the lung microenvironment and through complex signaling cascades, not only promotes neutrophil influx into the pleural space, thereby promoting the damaging hyperinflammatory environment, but simultaneously drives tissue destruction through upregulating matrix metalloproteases (MMPs) (17).

The literature indicates that various PI3-K isoforms play a significant role in shaping the Th17 response, however signaling through the various isoforms is still unclear, as well as the role they play in IL-17A secretion in TB $(4,23,24)$. It is established that IL-17A secretion and the expansion of the Th17 population is dependent on IL-23 (16), however downstream signaling is mediated by members of the PI3-Kinase family. Studies have shown that the PI3-Kinase pathway activates and is activated by IL-17A during a number of inflammatory diseases $(25,26)$, including TB $(17,27)$. It is noteworthy that transcriptomic studies have revealed that various members of the PI3-kinase family, such as PIK3CD, PIK3IP1, PIK3C2B are aberrantly expressed in patients with active TB compared to uninfected controls $(28,29)$. This review aims to clarify PI3-Kinase-mediated IL-17A signaling in the context of TB disease in various cell types and indicate how it mediates the Th17 response. In addition, the possibility of utilizing PI3K-isoform specific drugs which could hinder Th17 differentiation, and therefore IL-17A secretion during late-stage $\mathrm{TB}$ disease as a possible therapeutic option is explored.

\section{PI3-KINASES REGULATE IL-17 SECRETION AND T-CELL EXPANSION}

PI3-Kinases are fundamental intermediaries in immune cell signaling networks. They generate a phosphatidylinositol $(3,4,5)$ trisphosphate second messenger molecule which recruits protein kinases and other proteins to the plasma membrane, where they activate other downstream mediators that are important in cell differentiation, proliferation, migration, and survival. The class IA PI3Ks, namely $\mathrm{PI} 3 \mathrm{~K} \alpha, \mathrm{PI} 3 \mathrm{~K} \beta$, and $\mathrm{PI} 3 \mathrm{~K} \delta$ bind tyrosines phosphorylated by receptor-associated kinases, whereas $\mathrm{PI} 3 \mathrm{~K} \gamma$, the only class IB PI3K, is activated by $\mathrm{G}$ protein-coupled receptors (30). PI $3 \mathrm{~K} \delta$ and $\mathrm{PI} 3 \mathrm{~K} \gamma$ are expressed predominantly in leukocytes and have been studied intensively in the context of immune-mediated diseases. Further, both isoforms are required in some cellular responses such as the generation of ROS by neutrophils and the degranulation of mast cells, which suggests that the contribution of each isoform is coordinated at different stages (31-33).

The role of these isoforms in the context of the Th17 response in $\mathrm{TB}$ has been better defined in the last few years where the immunomodulatory role early on in infection is observed. Briefly, the presence of inhaled mycobacteria in the lung activates local bronchial epithelial cells (34) and phagocytosis by alveolar macrophages mediated by various receptors marks the commencement of the innate immune response during the early stages of infection (35). Fine orchestration of the release of chemokines and cytokines from these cells quickly recruits circulating immune cells such as neutrophils and lung $\gamma \delta \mathrm{T}$-cells to the site of infection which is then followed by effector T-cell populations (Figure 1A). Naïve $\mathrm{CD}^{+}{ }^{+} \mathrm{T}$-cells differentiate into Th17 cells after exposure to IL-1 $\beta$ and IL-23 (36), which in turn stimulate the secretion of IL-17A. TB-reactive T-cells residing in the lungs before M.tb exposure and those located systemically are recruited to the site of infection shortly after pulmonary $M . t b$ exposure, which is where the control of the initial infection begins (37). Activation of PI3-kinase signaling is initiated downstream of the T-cell receptor after its engagement with an antigen. The increment in T-cell populations and the related cytokines is a hallmark of the majority of immunological diseases, including TB. The significance of PI3-kinases in regulating the 


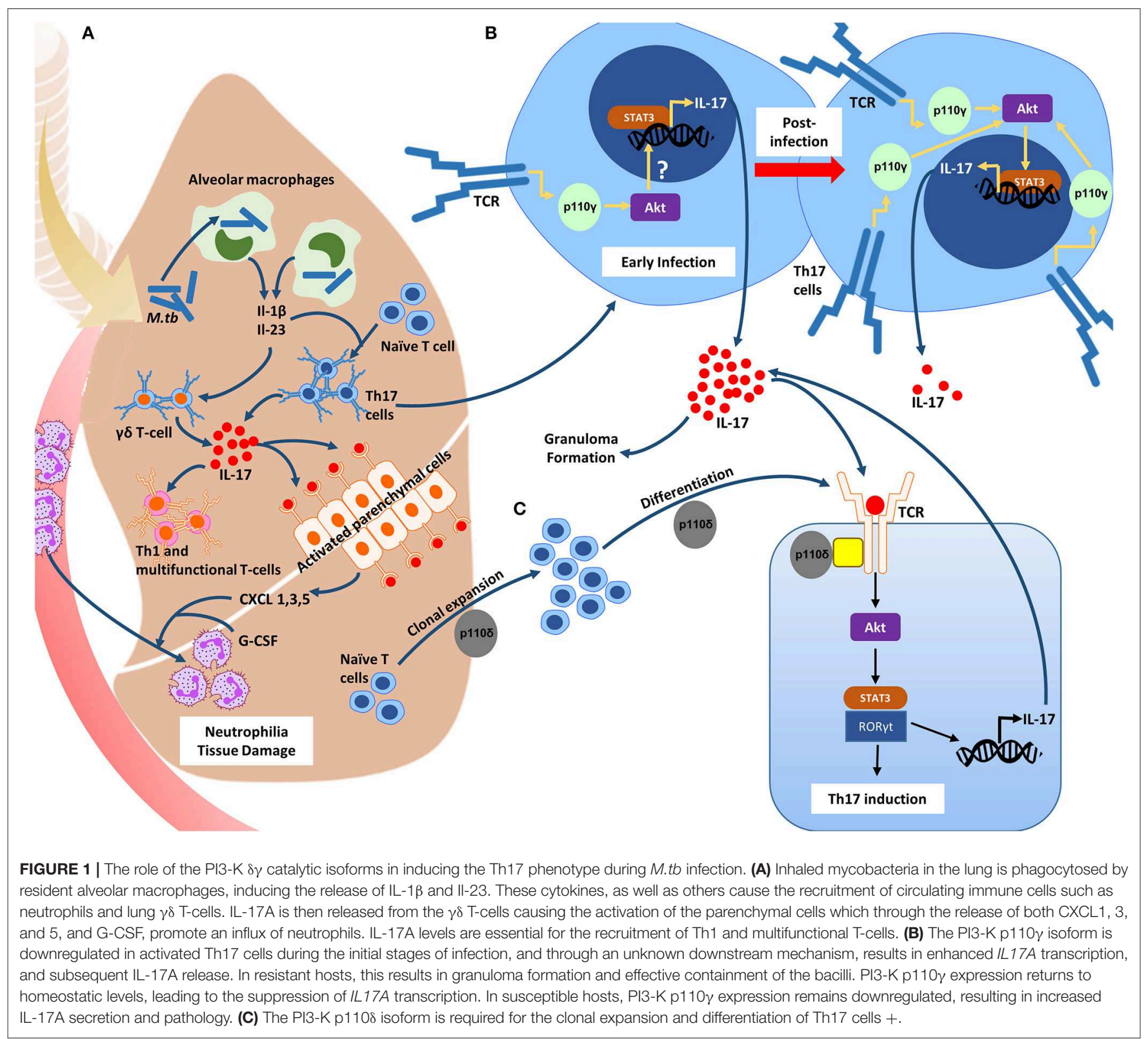

development, survival and differentiation of Th1, Th2, and Th17 cell subsets has been demonstrated.

\section{PI3-K p110 $\gamma$ Inhibits IL-17A Secretion During TB}

PI3K $\gamma$, a class IB isoform belonging to the PI3-Kinase family plays a prominent role in shaping the Th17 response during early infection with M.tb (Figure 1B). Studies in gene-deficient mice suggest that the presence of the p110 $\gamma$ isoform may promote susceptibility to infection and subsequent development of TB disease through dampening of the Th17 response (38-40). It was observed that PI3K $\gamma^{-1-}$ mice challenged intranasally with LPS had increased concentrations of IL-17A in their bronchoalveolar lavage fluid (39). Another group showed that spleen cell cultures stimulated with LPS revealed increased production of IL-17A by PI3K $\gamma$ - deficient T-cells (40). More recently, CavalcantiNeto et al. observed that mice deficient in this enzyme were resistant to M.tb infection and exhibited a robust Th17 response to which they attributed the improved resistance (38). In line with this, transcriptomics reveal that in patients with active TB, PIK3CG is downregulated compared to healthy controls (41), and those with latent TB (42) indicating a modulatory role for this isoform even during late stage disease. This data suggests that in resistant hosts, PI3K $\gamma$ may be downregulated initially in order to facilitate granuloma formation and resolution of the infection through IL-17A upregulation, and then regain homeostatic levels of expression after the resolution of the infection. In hosts which are susceptible to progress toward active disease, $\mathrm{PI} 3 \mathrm{~K} \gamma$ may be downregulated from the initial point of infection throughout the progression and establishment of disease resulting in the over 
secretion and therefore pathological potential of IL-17A. This dysregulated expression may be as a result of inherited genetic alterations in PIK3CG and/or dysregulation in the upstream or downstream signaling components which govern $\mathrm{PI} 3 \mathrm{~K} \gamma$ activation. This requires further investigation. Nevertheless, lower levels of the p110 $\gamma$ isoform likely contributes to the over-secretion and therefore the immunopathology of the IL$17 \mathrm{~A}$ response during $\mathrm{TB}$, and raises the question of whether $\mathrm{PI} 3 \mathrm{~K} \gamma$ classifies as a negative regulator of IL-17A during natural protective immunity toward M.tb infection.

\section{PI3-K p110 Is a Target of M.tb and Shapes the Th17 Response During TB}

Pharmacological studies together with genetic evidence have implicated dysfunctional PI3K signaling in airway inflammation, and studies exploring the potential therapeutic benefit of PI3K $\delta$ (class IA isoform) have yielded encouraging results (43). PI3K $\delta$ is an isoform of PI $3 \mathrm{~K} \gamma$ and lies downstream of tyrosine kinaseassociated receptors, T cell receptors (TCR), co-stimulatory, and cytokine receptors, depending on the cell type. The role of PI3K $\delta$ in macrophages and T-cells during M.tb infection is discussed below.

Recent work has found that during macrophage infection, $M . t b$ upregulates miRNAs that target mRNAs encoding PI3K $\delta$, mTORC-1, and MNK-1 (44). By disrupting the genes encoding PI3-K $\delta / A K T / m T O R C 1$ and MNK regulatory pathways, matrix metalloproteinase (MMP) expression, specifically MMP-1, is upregulated. In doing so, M.tb alters the normal protective response of the macrophage toward a tissue destructive phenotype through MMP expression. In the same study the authors observed that the expression of PI $3 \mathrm{~K} \delta$ is globally absent throughout TB granulomas, but present in normal lung tissue from healthy individuals (44). Knock-out studies found that p $110 \gamma / \delta^{-/-}$mice had increased IL-17A serum concentrations and frequencies of IL-17A+ splenic T-cells and that a deficiency in either the $\gamma$ or $\delta$ isoform disrupts the IL-17A/G-CSF axis which results in neutrophilia (27). Evidence suggests that this decrease or loss in function of PI3K $\delta$ enhances IL-17A and IL-17Aproducing T-cells. In contrast, inhibition of $\mathrm{PI} 3 \mathrm{~K} \delta$ suppresses IL-17A expression through the regulation of NF-kB activity in a murine model of asthma (45) and in imiquimod-induced psoriasis-like dermatitis (6). Recently, a disease related to a gain of function mutation in $\mathrm{PI} 3 \mathrm{~K} \delta$ was described (46). In activated PI3K $\delta$ syndrome (APDS), over expression of PI3K $\delta$ in these individuals predisposes them to respiratory infections and airway damage. Thus, both a gain or loss in function of PI3K $\delta$ significantly affects the Th17 response during an infectious or inflammatory episode and plays an important role in immunopathology of various disease states.

The signaling pathways responsible for T-cell differentiation are numerous, however the importance of the PI3-Kinase pathway in orchestrating differentiation of these cells has been noted previously $(25,26,47-50)$. PI $3 \mathrm{~K} \delta$ specifically is of interest since its preferentially expressed in leukocytes and is essential for $\mathrm{CD}_{4}^{+}$T-cell clonal expansion and differentiation (51). Naïve cells differentiate into Th17 cells following stimulation of their T-cell receptor (TCR) by antigen exposure or to IL-1 $\beta$ and IL-23 stimulation (36). Upon stimulation, the TCR causes PI3-K $\delta$ activation through TCR costimulatory and adaptor proteins $(51,52)$ which then generates phosphatidylinositol-3,4,5-trisphosphate (PIP3) by phosphorylating phosphatidylinositol-4,5-bisphosphate at the plasma membrane. PIP3 then recruits AKT to the plasma membrane inducing its phosphorylation where it initiates various cellular functions. Recently it was observed that PI3K $\delta$ induces IL-17A secretion from committed Th17 cells (Figure 1C), and that inhibiting this isoform not only suppresses IL-17A secretion from Th17 cells, but also inhibits cytokine production from multiple T-helper cell types (48). The same study confirmed that PI3K $\delta$ mediated IL-17A release from pulmonary $\gamma \delta$ T-cells, and thus appears to be a key molecule in the IL-17A signaling cascade. Inhibition of PI3-K $\delta$ in vivo also resulted in a decrease in neutrophil recruitment to the lung and therefore in the BAL fluid of mice. No effect was observed in macrophages and other cells which demonstrates the link between PI3K $\delta$, IL-17A, and neutrophil trafficking (48).

As a consequence of dysregulated IL-17A signaling resulting from changes in the expression of PI $3 \mathrm{~K} \delta$ or PI3K $\gamma$, exacerbated neutrophil influx into the pleural space is commonly observed during late stage TB (53). Further, aberrant expression of these genes and other PI3-K family members cause disruptions in neutrophil trafficking that lead to neutrophil hyperreactivity through directly compromising their migratory accuracy. This results in prolonged tissue transit time which leads to bystander tissue injury mediated by surface-associated neutrophil proteases and further secretion of IL-17A (54). Targeting of the p1108 isoform that control neutrophil influx and IL-17A may be a therapeutic option for patients with TB.

\section{IS THE INHIBITION OF P110 $\delta$ ISOFORM AN OPTION FOR THE TREATMENT OF TB?}

The benefit of targeting PI3K isoforms has received considerable attention and is being viewed as a viable therapeutic option in inflammatory and infectious lung disorders. The comprehensive role of PI3K $\delta$ and PI3K $\gamma$ in the ordinance of immunological mechanisms has presented them as potential targets for the treatment of immunological diseases such as autoimmune and allergic diseases $(55,56)$. Examples of this include PI3K $\delta$ inhibitors to suppress the progression of inflammation and reduce the severity of rheumatoid arthritis and systemic lupus erythematosus in murine models (57). The selective PI3K $\gamma$ inhibitor AS605240 was shown in vitro and in vivo to reverse autoimmune diabetes in non-obese diabetic mice and inhibit T-cell cytokine release (58). In the context of TB, Th1 along with Th17 are the main effector populations which mediate both protection and pathology during the early and late stages of disease progression $(9,59)$. Thorough investigation of the functions of PI $3 \mathrm{~K} \delta$ and PI $3 \mathrm{~K} \gamma$ in tuberculosis and other disease models, as well as in patient tissues, will be crucial to validate them as targets for the treatment of a range of inflammatory diseases. As mentioned previously, dysregulated IL-17A secretion 
is also observed to be increased in the airways of COPD patients and severe asthmatics which coordinate neutrophilic inflammation in these diseases. Although neutrophilia is an overwhelming feature of these diseases, targeting of these cells may not be effective. It was observed that therapies directed at neutrophil-derived products have limited efficacy and are only effective exceptional circumstances $(60,61)$. The p110 $\delta$ isoform has been implicated in airway inflammation, with selective targeting of this isoform yielding promising results in COPD and asthma by broadly reducing lymphocyte-derived cytokines such as IL-17A, and suppressing ROS release from neutrophils $(43,62,63)$. Specifically, p110 inhibition demonstrates that $\mathrm{T}$ lymphocyte-derived cytokine generation can be suppressed with multiple T-cell lineages targeted (48), as well as Th17 differentiation (48). Recently, a clinical study on APDS patients was conducted using the oral PI $3 \mathrm{~K} \delta$ selective inhibitor Leniolisib which aimed to "normalize" the augmented PI3K $\delta$ activity rather than to completely inhibit it. This resulted in some clinical benefit in a short-term study, without significant toxicity to the patient (64).

In $\mathrm{TB}$ patients it is imperative that IL-17A secretion is not completely abolished as this cytokine is required for a certain level of M.tb control and granuloma turn over. Further, an inhalable form of this inhibitor, for use in asthma patients may be a viable option. The above evidence suggests that targeting of this isoform may yield positive results. It is more likely that by dampening the Th17 response, which includes neutrophil influx, tissue damage will be reduced. In this way, long-term pulmonary damage from fibrotic scar tissue development may be subverted, however the resulting effect on $M . t b$ survival is unclear and requires further investigation. Although IL-17A does exhibit protective effects, particularly against hypervirulent $M . t b$ strains, the option of enhancing IL-17, particularly during latestage $\mathrm{TB}$ disease may potentiate and exacerbate auto-immune responses and chronic inflammation. Further investigation into the Th17 response during late-stage TB is required to increase our understanding on the dynamic changes in IL17 signaling during this complex disease.

\section{OUTSTANDING QUESTIONS AND CHALLENGES}

An important step would begin with investigations in the lung and pulmonary compartment of TB patients as this will reveal

\section{REFERENCES}

1. Happel KI, Dubin PJ, Zheng M, Ghilardi N, Lockhart C, Quinton LJ, et al. Divergent roles of IL-23 and IL-12 in host defense against Klebsiella pneumoniae. J Exp Med. (2005) 202:761-9. doi: 10.1084/jem.20050193

2. Ye P, Garvey PB, Zhang P, Nelson S, Bagby G, Summer WR, et al. Interleukin17 and lung host defense against Klebsiella pneumoniae infection. Am J Respir Cell Mol Biol. (2001) 25:335-40. doi: 10.1165/ajrcmb.25.3.4424

3. Fogli LK, Sundrud MS, Goel S, Bajwa S, Jensen K, Derudder E, et al. T cell-derived IL-17 mediates epithelial changes in the airway unique characteristics of this niche which are distinct from what is observed in the blood. For example there is evidence supporting the fact that Th17-like cells and Th17- related cytokines are remarkably different from those observed from the blood in TB patients (64). Thus, better characterization of the Th17 cellular response in TB pulmonary compartments is needed. Since Th17 cells and their related cytokines are increased in pulmonary tissue and BAL during late-stage disease (17), an inhalable $\mathrm{p} 110 \delta$ isoform inhibitor is a therapeutic treatment option as an adjunct to standard antibiotics. To date, the use of p110 $\delta$ isoform inhibitors as an adjunct to standard therapy have not been proposed for the treatment of TB, thus many unanswered questions remain as to whether this is a viable option. Inflammatory airway diseases with an inflammatory cytokine profile similar to that of $\mathrm{TB}$, which is driven specifically by IL-17A oversecretion, appear to be resolved with the use of a p $110 \delta$ inhibitor such as Leniolisib. Extended studies are required to evaluate outcomes such as respiratory infection and inflammation, and to establish the safety of long-term treatment of the drug. Evidence suggests that PI3K $\delta$ and $\mathrm{PI} 3 \mathrm{~K} \gamma$ synchronize in distinct, yet interdependent signaling pathways in many immune cells. Their fine-tuned integration gives rise to pro-inflammatory events in the multistep pathogenic process of inflammation. To date, it is unknown how the expression of these isoforms are regulated in response to one another, as well as other isoforms, particularly during TB. A key question that remains is whether both $\mathrm{PI} 3 \mathrm{~K} \delta$ and $\mathrm{PI} 3 \mathrm{~K} \gamma$ are valid targets for the treatment of chronic inflammatory diseases such as tuberculosis or whether one would be more suitable than the other. Further, the presence of M.tb in the lungs of TB patients receiving the proposed treatment raises further questions: (1) will a reduction in IL-17A levels provide a niche more suitable for $M . t b$ replication, or (2) will it reduce neutrophil recruitment to the lung compartment, thereby promoting the generation of a stable mononuclear granuloma?

\section{AUTHOR CONTRIBUTIONS}

The author confirms being the sole contributor of this work and has approved it for publication.

\section{FUNDING}

This work was funded by the South African Medical Research Council and the National Research Foundation of South Africa. and drives pulmonary neutrophilia. J Immunol. (2013) 2013:1301360. doi: 10.4049/jimmunol.1390058

4. Song X, Qian Y. IL-17 family cytokines mediated signaling in the pathogenesis of inflammatory diseases. Cell Signal. (2013) 25:2335-47. doi: 10.1016/j.cellsig.2013.07.021

5. Chen F, Cao A, Yao S, Evans-Marin HL, Liu H, Wu W, et al. mTOR mediates IL-23 induction of neutrophil IL-17 and IL-22 production. J Immunol. (2016) 196:4390-9. doi: 10.4049/jimmunol.1501541

6. Roller A, Perino A, Dapavo P, Soro E, Okkenhaug K, Hirsch E, et al. Blockade of phosphatidylinositol 3-kinase (PI3K) $\delta$ or PI3K $\gamma$ reduces IL-17 
and ameliorates imiquimod-induced psoriasis-like dermatitis. J Immunol. (2012) 189:4612-20. doi: 10.4049/jimmunol.1103173

7. McGeachy MJ, Cua DJ, Gaffen SL. The IL-17 family of cytokines in health and disease. Immunity. (2019) 50:892-906. doi: 10.1016/j.immuni.2019.03.021

8. Jones SA, Sutton CE, Cua D, Mills KH. Therapeutic potential of targeting IL-17. Nat Immunol. (2012) 13:1022-5. doi: 10.1038/ni.2450

9. Torrado E, Cooper AM. IL-17 and Th17 cells in tuberculosis. Cytokine Growth Factor Rev. (2010) 21:455-62. doi: 10.1016/j.cytogfr.2010.10.004

10. Yoshida YO, Umemura M, Yahagi A, O’Brien RL, Ikuta K, Kishihara $\mathrm{K}$, et al. Essential role of IL-17A in the formation of a mycobacterial infection-induced granuloma in the lung. J Immunol. (2010) 184:4414-22. doi: 10.4049/jimmunol.0903332

11. Umemura M, Yahagi A, Hamada S, Begum MD, Watanabe H, Kawakami K, et al. IL-17-mediated regulation of innate and acquired immune response against pulmonary Mycobacterium bovis bacille Calmette-Guerin infection. $J$ Immunol. (2007) 178:3786-96. doi: 10.4049/jimmunol.178.6.3786

12. Gopal R, Monin L, Slight S, Uche U, Blanchard E, Junecko BAF, et al. Unexpected role for IL-17 in protective immunity against hypervirulent Mycobacterium tuberculosis HN878 infection. PLoS Pathog. (2014) 10:e1004099. doi: 10.1371/journal.ppat.1004099

13. Erdmann H, Behrends J, Ritter K, Hölscher A, Volz J, Rosenkrands I, et al. The increased protection and pathology in Mycobacterium tuberculosis-infected IL-27R-alpha-deficient mice is supported by IL-17A and is associated with the IL-17A-induced expansion of multifunctional T cells. Mucosal Immunol. (2018) 11:1168-80. doi: 10.1038/s41385-018-0026-3

14. Gopal R, Rangel-Moreno J, Slight S, Lin Y, Nawar HF, Junecko BF, et al. Interleukin-17-dependent CXCL13 mediates mucosal vaccineinduced immunity against tuberculosis. Mucosal Immunol. (2013) 6:972. doi: $10.1038 / \mathrm{mi} .2012 .135$

15. Cruz A, Fraga AG, Fountain JJ, Rangel-Moreno J, Torrado E, Saraiva M, et al. Pathological role of interleukin 17 in mice subjected to repeated BCG vaccination after infection with Mycobacterium tuberculosis. J Exp Med. (2010) 207:1609-16. doi: 10.1084/jem.20100265

16. Khader SA, Cooper AM. IL-23 and IL-17 in tuberculosis. Cytokine. (2008) 41:79-83. doi: 10.1016/j.cyto.2007.11.022

17. Singh S, Maniakis-Grivas G, Singh UK, Asher RM, Mauri F, Elkington PT, et al. Interleukin-17 regulates matrix metalloproteinase activity in human pulmonary tuberculosis. J Pathol. (2018) 244:311-22. doi: 10.1002/path.5013

18. Lombard R, Doz E, Carreras F, Epardaud M, Le Vern Y, Buzoni-Gatel $\mathrm{D}$, et al. IL-17RA in non-hematopoietic cells controls CXCL-1 and 5 critical to recruit neutrophils to the lung of mycobacteria-infected mice during the adaptive immune response. PLOS ONE. (2016) 11:e0149455. doi: 10.1371/journal.pone.0149455

19. Xu L, Cui G, Jia H, Zhu Y, Ding Y, Chen J, et al. Decreased IL-17 during treatment of sputum smear-positive pulmonary tuberculosis due to increased regulatory T cells and IL-10. J Transl Med. (2016) 14:179. doi: 10.1186/s12967-016-0909-6

20. Coulter F, Parrish A, Manning D, Kampmann B, Mendy J, Garand M, et al. IL-17 production from T helper 17, mucosal-associated invariant T, and $\gamma \delta$ cells in tuberculosis infection and disease. Front Immunol. (2017) 8:1252. doi: 10.3389/fimmu.2017.01252

21. Li Q, Li J, Tian J, Zhu B, Zhang Y, Yang K, et al. IL-17 and IFN- $\gamma$ production in peripheral blood following BCG vaccination and Mycobacterium tuberculosis infection in human. Eur Rev Med Pharmacol Sci. (2012) 16:2029-36.

22. Keller C, Hoffmann R, Lang R, Brandau S, Hermann C, Ehlers S. Genetically determined susceptibility to tuberculosis in mice causally involves accelerated and enhanced recruitment of granulocytes. Infect Immun. (2006) 74:4295309. doi: 10.1128/IAI.00057-06

23. Song C, Hsu K, Yamen E, Yan W, Fock J, Witting PK, et al. Serum amyloid A induction of cytokines in monocytes/macrophages and lymphocytes. Atherosclerosis. (2009) 207:374-83. doi: 10.1016/j.atherosclerosis.2009. 05.007

24. Huang F, Kao C-Y, Wachi S, Thai P, Ryu J, Wu R. Requirement for both JAK-mediated PI3K signaling and ACT1/TRAF6/TAK1dependent NF- $\mathrm{KB}$ activation by IL-17A in enhancing cytokine expression in human airway epithelial cells. J Immunol. (2007) 179:6504-13. doi: 10.4049/jimmunol.179.10.6504
25. Handi J, Patterson SJ, Levings M. The role of the PI3K signaling pathway in CD4+ T cell differentiation and function. Front Immunol. (2012) 3:245. doi: 10.3389/fimmu. 2012.00245

26. Kurebayashi Y, Nagai S, Ikejiri A, Ohtani M, Ichiyama K, Baba Y, et al. PI3KAkt-mTORC1-S6K1/2 axis controls Th17 differentiation by regulating Gfil expression and nuclear translocation of ROR $\gamma$. Cell Rep. (2012) 1:360-73. doi: 10.1016/j.celrep.2012.02.007

27. Bucher K, Schmitt F, Mothes B, Blumendeller C, Schäll D, Piekorz R, et al. Deficiency of PI3-Kinase catalytic isoforms p $110 \gamma$ and p $110 \delta$ in mice enhances the IL-17/G-CSF axis and induces neutrophilia. Cell Commun Signal. (2017) 15:28. doi: 10.1186/s12964-017-0185-y

28. Leisching GR. Susceptibility to tuberculosis is associated with PI3Kdependent increased mobilization of neutrophils. Front Immunol. (2018) 9:1669. doi: 10.3389/fimmu.2018.01669

29. Maertzdorf J, Repsilber D, Parida SK, Stanley K, Roberts T, Black G, et al. Human gene expression profiles of susceptibility and resistance in tuberculosis. Genes Immun. (2011) 12:15. doi: 10.1038/gene.2010.51

30. Rommel C, Camps M, Ji H. PI3K $\delta$ and PI $3 \mathrm{~K} \gamma$ : partners in crime in inflammation in rheumatoid arthritis and beyond? Nat Rev Immunol. (2007) 7:191-201. doi: 10.1038/nri2036

31. Sasaki T, Irie-Sasaki J, Jones RG, Oliveira-dos-Santos AJ, Stanford WL, Bolon B, et al. Function of $\mathrm{PI} 3 \mathrm{~K} \gamma$ in thymocyte development, $\mathrm{T}$ cell activation, and neutrophil migration. Science. (2000) 287:1040-6. doi: 10.1126/science.287.5455.1040

32. Ali K, Bilancio A, Thomas M, Pearce W, Gilfillan AM, Tkaczyk C, et al Essential role for the p110 8 phosphoinositide 3-kinase in the allergic response. Nature. (2004) 431:1007. doi: 10.1038/nature02991

33. Laffargue M, Calvez R, Finan P, Trifilieff A, Barbier M, Altruda F, et al. Phosphoinositide 3-kinase $\gamma$ is an essential amplifier of mast cell function. Immunity. (2002) 16:441-51. doi: 10.1016/S1074-7613(02)00282-0

34. Sauty A, Dziejman M, Taha RA, Iarossi AS, Neote K, Garcia-Zepeda EA, et al. The T cell-specific CXC chemokines IP-10, Mig, and I-TAC are expressed by activated human bronchial epithelial cells. J Immunol. (1999) 162:3549-58.

35. Ernst JD. Macrophage receptors for Mycobacterium tuberculosis. Infect Immun. (1998) 66:1277-81.

36. McGeachy MJ, Cua DJ. Th17 cell differentiation: the long and winding road. Immunity. (2008) 28:445-53. doi: 10.1016/j.immuni.2008.03.001

37. Cooper AM. T cells in mycobacterial infection and disease. Curr Opin Immunol. (2009) 21:378-84. doi: 10.1016/j.coi.2009.06.004

38. Cavalcanti-Neto M, Prado R, Piñeros A, Sérgio C, Bertolini T, Gembre $\mathrm{A}$, et al. Improvement of the resistance against early Mycobacterium tuberculosis-infection in the absence of PI3K $\gamma$ enzyme is associated with increase of CD4+ IL-17+ cells and neutrophils. Tuberculosis. (2018) 113:1-9. doi: 10.1016/j.tube.2018.08.009

39. Xu Y, Loison F, Luo HR. Neutrophil spontaneous death is mediated by downregulation of autocrine signaling through GPCR, PI $3 \mathrm{~K} \gamma$, ROS, and actin. Proc Natl Acad Sci USA. (2010) 107:2950-5. doi: 10.1073/pnas.0912717107

40. Harris SJ, Ciuclan L, Finan PM, Wymann MP, Walker C, Westwick J, et al. Genetic ablation of PI3K $\gamma$ results in defective IL-17RA signaling in T lymphocytes and increased IL-17 levels. Eur J Immunol. (2012) 42:3394-404. doi: 10.1002/eji.201242463

41. Lesho E, Forestiero FJ, Hirata MH, Hirata RD, Cecon L, Melo FF, et al. Transcriptional responses of host peripheral blood cells to tuberculosis infection. Tuberculosis. (2011) 91:390-9. doi: 10.1016/j.tube.2011.07.002

42. Lee S-W, Wu LS-H, Huang G-M, Huang K-Y, Lee T-Y, Weng JTY. Gene expression profiling identifies candidate biomarkers for active and latent tuberculosis. BMC Bioinformatics. (2016) 17:S3. doi: 10.1186/s12859-015-0848-x

43. Stokes CA, Condliffe AM. Phosphoinositide 3-kinase $\delta$ (PI3K $\delta$ ) in respiratory disease. Biochem Soc Transl. (2018) 46:361-9. doi: 10.1042/BST20170467

44. Brace PT, Tezera LB, Bielecka MK, Mellows T, Garay D, Tian S, et al. Mycobacterium tuberculosis subverts negative regulatory pathways in human macrophages to drive immunopathology. PLoS Pathog. (2017) 13:e1006367. doi: 10.1371/journal.ppat.1006367

45. Park S-J, Lee KS, Kim SR, Min KH, Moon H, Lee MH, et al. Phosphoinositide 3-kinase $\delta$ inhibitor suppresses interleukin-17 expression in a murine asthma model. Eur Respir J. (2010) 36:1448-59. doi: 10.1183/09031936.00106609 
46. Angulo I, Vadas O, Garçon F, Banham-Hall E, Plagnol V, Leahy TR, et al. Phosphoinositide 3-kinase $\delta$ gene mutation predisposes to respiratory infection and airway damage. Science. (2013) 342:866-71. doi: $10.1126 /$ science. 1243292

47. Nagai S, Kurebayashi Y, Koyasu S. Role of PI3K/Akt and mTOR complexes in Th17 cell differentiation. Ann N Y Acad Sci. (2013) 1280:30-4. doi: $10.1111 /$ nyas. 12059

48. Way EE, Trevejo-Nunez G, Kane LP, Steiner BH, Puri KD, Kolls JK, et al. Dose-dependent suppression of cytokine production from $\mathrm{T}$ cells by a novel phosphoinositide 3-kinase delta inhibitor. Sci Rep. (2016) 6:30384. doi: 10.1038/srep30384

49. Chen X, Guo Y, Han R, Liu H, Ding Y, Shi Y, et al. Class I PI3K inhibitor ZSTK474 attenuates experimental autoimmune neuritis by decreasing the frequency of Th1/Th17 cells and reducing the production of proinflammatory cytokines. Cell Immunol. (2018) 329:41-9. doi: 10.1016/j.cellimm.2018.04.011

50. Yin N, Wang Y, Lu X, Liu R, Zhang L, Zhao W, et al. hPMSC transplantation restoring ovarian function in premature ovarian failure mice is associated with change of Th17/Tc17 and Th17/Treg cell ratios through the PI3K/Akt signal pathway. Stem Cell Res Ther. (2018) 9:37. doi: 10.1186/s13287-0180772-x

51. Okkenhaug K, Vanhaesebroeck B. PI3K in lymphocyte development, differentiation and activation. Nat Rev Immunol. (2003) 3:317. doi: $10.1038 /$ nri1056

52. Okkenhaug K, Patton DT, Bilancio A, Garçon F, Rowan WC, Vanhaesebroeck B. The p110 isoform of phosphoinositide 3-kinase controls clonal expansion and differentiation of Th cells. J Immunol. (2006) 177:5122-8. doi: 10.4049/jimmunol.177.8.5122

53. Philips JA. Neutrophils: double agents for TB. Sci Transl Med. (2017) 9:eaan6195. doi: 10.1126/scitranslmed.aan6195

54. Sapey E, Greenwood H, Walton G, Mann E, Love A, Aaronson N, et al. Phosphoinositide 3-kinase inhibition restores neutrophil accuracy in the elderly: toward targeted treatments for immunosenescence. Blood. (2014) 123:239-48. doi: 10.1182/blood-2013-08-519520

55. Randis TM, Puri KD, Zhou H, Diacovo TG. Role of PI $3 \mathrm{~K} \delta$ and PI $3 \mathrm{~K} \gamma$ in inflammatory arthritis and tissue localization of neutrophils. Eur J Immunol. (2008) 38:1215-24. doi: 10.1002/eji.200838266

56. Maxwell MJ, Tsantikos E, Kong AM, Vanhaesebroeck B, Tarlinton DM, Hibbs ML. Attenuation of phosphoinositide 3-kinase $\delta$ signaling restrains autoimmune disease. J Autoimmun. (2012) 38:381-91. doi: 10.1016/j.jaut.2012.04.001
57. Haselmayer P, Camps M, Muzerelle M, El Bawab S, Waltzinger C, Bruns L, et al. Characterization of novel PI3K $\delta$ inhibitors as potential therapeutics for SLE and lupus nephritis in pre-clinical studies. Front Immunol. (2014) 5:233. doi: 10.3389/fimmu.2014.00233

58. Azzi J, Moore RF, Elyaman W, Mounayar M, El Haddad N, Yang S, et al. The novel therapeutic effect of phosphoinositide 3-kinase- $\gamma$ inhibitor AS605240 in autoimmune diabetes. Diabetes. (2012) 61:1509-18. doi: 10.2337/db11-0134

59. Freches D, Korf H, Denis O, Havaux X, Huygen K, Romano M. Mice genetically inactivated in interleukin-17 A receptor are defective in longterm control of Mycobacterium tuberculosis infection. Immunology. (2013) 140:220-31. doi: 10.1111/imm.12130

60. Nordenmark LH, Taylor R, Jorup C. Feasibility of computed tomography in a multicenter COPD trial: a study of the effect of AZD9668 on structural airway changes. Adv Ther. (2015) 32:548-66. doi: 10.1007/s12325-015-0215-3

61. Stockley R, De Soyza A, Gunawardena K, Perrett J, Forsman-Semb K, Entwistle N, et al. Phase II study of a neutrophil elastase inhibitor (AZD9668) in patients with bronchiectasis. Respir Med. (2013) 107:524-33. doi: 10.1016/j.rmed.2012.12.009

62. Southworth T, Plumb J, Gupta V, Pearson J, Ramis I, Lehner MD, et al. Antiinflammatory potential of PI3K $\delta$ and JAK inhibitors in asthma patients. Respir Res. (2016) 17:124. doi: 10.1186/s12931-016-0436-2

63. Khan A, Southworth T, Worsley S, Sriskantharajah S, Amour A, Hessel $\mathrm{EM}$, et al. An investigation of the anti-inflammatory effects and a potential biomarker of PI3K $\delta$ inhibition in COPD T cells. Clin Exp Pharmacol Physiol. (2017) 44:932-40. doi: 10.1111/1440-1681.12784

64. Rao VK, Webster S, Dalm VA, Šedivá A, van Hagen PM, Holland $\mathrm{S}$, et al. Effective "activated PI3K $\delta$ syndrome"-targeted therapy with the PI3K $\delta$ inhibitor leniolisib. Blood. (2017) 130:2307-16. doi: 10.1182/blood-2017-08-801191

Conflict of Interest: The author declares that the research was conducted in the absence of any commercial or financial relationships that could be construed as a potential conflict of interest.

Copyright (C) 2019 Leisching. This is an open-access article distributed under the terms of the Creative Commons Attribution License (CC BY). The use, distribution or reproduction in other forums is permitted, provided the original author(s) and the copyright owner(s) are credited and that the original publication in this journal is cited, in accordance with accepted academic practice. No use, distribution or reproduction is permitted which does not comply with these terms. 